\title{
Review
}

\section{Management of Behavioral and Psychological Symptoms of Dementia}

\author{
Eylem ŞAHIN CANKURTARAN \\ Dışkapı Yıldırım Beyazıt Training and Research Hospital, Clinic of Psychiatry, Ankara, Turkey
}

\begin{abstract}

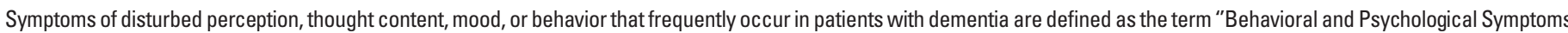

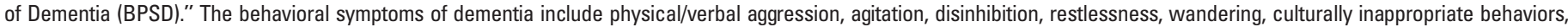

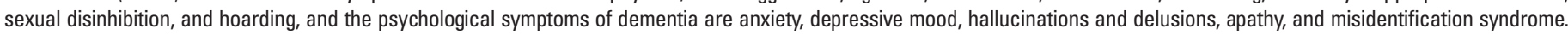

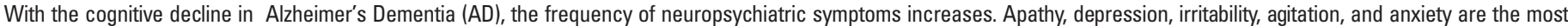

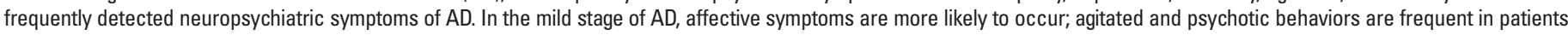

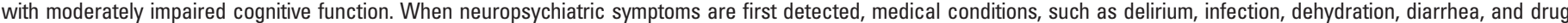

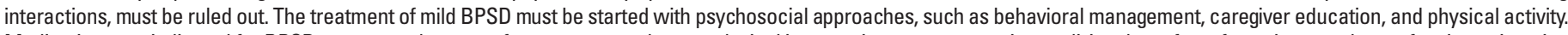

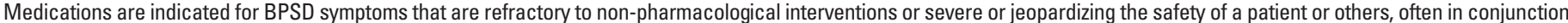
with non-pharmacological interventions. (Archives of Neuropsychiatry 2014; 51: 303-312)
\end{abstract}

Key words: Alzheimer dementia, behavioral and psychological symptoms of dementia, elderly

Conflict of Interest: The authors reported no conflict of interest related to this article.

As the global population ages and as life expectancy increases, the prevalence of dementia also increases. There are nearly 35.6 million people with dementia worldwide in 2010, which is estimated to nearly double every 20 years and is expected to reach nearly 115 million by the year 2050 (1).

Alzheimer's disease, the most common form of the dementia, is a devastating disease resulting in a progressive decline in cognition and function. Furthermore, over the course of the illness, nearly $97 \%$ of patients develop behavioral or psychiatric symptoms (2), which are referred to as "Behavioral and Psychological Symptoms of Dementia (BPSD)." The International Psychogeriatrics Association consensus group defined the term BPSD as "symptoms of disturbed perception, thought content, mood, or behavior that frequently occur in patients with dementia (3)."

There has been ongoing research for identifying models for characterizing BPSD symptoms neurobiologically; however, they have been (3) simply grouped as behavioral and psychological symptoms, which are summarized in Table 1 (4).

The overall frequency of BPSD in patients with Alzheimer's disease living in the community is $56 \%-98 \%$ and $91 \%-96 \%$ in care facilities, such as nursing homes $(5,6)$. Behavioral and psychological symptoms of dementia cause significant distress both for the patients and for the caregivers $(6,7)$ and are also a precipitating factor for nursing home care (8). These symptoms are associated not only with burden but also with survival of patients. In a prospective study of 3 years, it was reported that as the number of the BPSD increases (especially the psychotic symptoms), the mortality rate of patients with Alzheimer's disease also increases (9). The most prevalent BPSD symptoms were apathy, depression, and delusions, and the most enduring symptom of BPSD was agitation in a 5 -year prevalence study (5). 


\section{Table 1. Behavioral and psychological symptoms of dementia}

\section{Behavioral symptoms \\ (Usually identified on the basis \\ of observation of the patient)}

\section{Psychological symptoms}

(Usually and mainly assessed on the basis of interviews with patients and relatives)

Physical aggression

Anxiety

Screaming

Depressive mood

Restlessness

Apathy

Agitation/Catastrophic reactions

(Verbal/Physical)

Hallucinations and delusions

(Psychosis of Alzheimer's Disease)

Wandering

Misidentification syndromes

Culturally inappropriate behaviors Sundowning

Sexual disinhibition

Elation

Hoarding

Negativism

Cursing

\section{The Assessment of the Behavioral and Psychological}

\section{Symptoms of Dementia}

The management of BPSD must begin with a broad clinical assessment and getting information from a reliable caregiver, besides examining the patient. The clinician must ask the caregiver about the most burdensome symptoms, because the symptom that seems to be problematic for the clinician may not be an issue for the caregiver. So, the clinician could be aware of the most distressing symptom, which is to be preferentially treated.

Besides that, the caregiver-patient interaction also interferes with BPSD symptoms, such as caregivers who are younger, less educated, more depressed, more burdened, (10). So, the clinician must take into consideration that the caregiver characteristics could influence the BPSD when managing Alzheimer's dementia.

The caregivers are sometimes prone to mention only the burdensome symptoms during the assessment of the patient; thus, an objective assessment with a reliable scale, such as the Neuropsychiatric Inventory, is preferred $(11,12)$. The Neuropsychiatric Inventory is the most extensively used scale for BPSD, for which many different versions are also available, such as Neuropsychiatric Inventory-Nursing Home (NPI-NH; for patients living in nursing homes), NPI- Questionnaire (a shorter form, NPI-0) and NPI- Clinician (a form in which assessment is made not only by the caregiver but also by the clinician and the patient, as well) (12).

Treatment of the Behavioral and Psychological Symptoms of Dementia: If any BPSD emerges for the first time, before considering any non-pharmacological or pharmacological therapies, physical health problems must be screened thoroughly, because physical health problems, such as urinary tract-chestdental infections, diarrhea, dehydration, and pain, may precipitate BPSD symptoms (13). For example, urinary tract infections are atypical or asymptomatic in elderly with dementia or silently come into sight. Also, patients can not declare their symptoms properly; so, it is difficult to detect these infections, which, in the course of time, cause BPSD symptoms and even delirium (13). Another precipitating factor for BPSD is visual and auditory impairments, which have been correlated with delusions and visual hallucinations (14). The drug-drug interactions must be also overviewed to elicit any side effects inducing BPSD symptoms, such as hyponatremia caused by serotoninergic antidepressants, which may cause agitation or confusion.

After screening any physical health problem or drug-induced side effects that may precipitate BPSD, the symptoms of BPSD that are not so severe must be evaluated with non-pharmacological interventions $(15,16,17)$. Optimizing the anti-dementia drugs is also recommended as the next step, because psychotropics are not yet perfectly suitable for the treatment of BPSD due to not having enough efficacy, such as antipsychotics and antidepressants. Besides, having many serious side effects, such as stroke, myocard infarctus and pnuomonia in dementia patients limits the usage of the antipsychotics.

If BPSD can not be controlled/reduced by the non-pharmacological interventions or if BPSD are so severe that it may cause harm to the patient or the caregiver, pharmacological treatment must be considered with on-going non-pharmacological interventions (17). The algorithm for the treatment for the BPSD of Alzheimer's dementia is shown in Figure $1(17,18,19,20)$.

\section{Non-Pharmacological Treatments of BPSD}

As mentioned before, non-pharmacological treatment strategies are recommended as the firstline management strategy for BPSD by many guidelines (17), such as the Americ an Association for Geriatric Psychiatry (21) and American Geriatric Society (18). There have been many different types of non-pharmacological interventions for the BPSD, which are listed in Table $2(22,23,24)$. According to the meta-analysis conducted by Brodaty et al. (22), nonpharmacological interventions were effective in reducing behavioral and psychological symptoms, with an overall effect size of .34 (95\% $\mathrm{Cl}=.20-.48 ; \mathrm{z}=4.87 ; \mathrm{p}<.01)$, as well as in ameliorating caregiver reactions to these behaviors, with an overall effect size of $.15(95 \% \mathrm{Cl}=.04-0.26 ; z=2.76 ; \mathrm{p}=.006)$. Another systematic review examining the non-pharmacological interventions identified a modest effect of behavior management therapies, education of the caregiver and the staf of nursing home, and also the cognitive stimulation techniques (25). However, the effect of cognitive rehabilitation was not longstanding in the studies (26) and also needs equipment and education, which are not yet practical. Emerging evidence about alternative and easy-to-use non-pharmacological interventions, such as aromatherapy with lavender oil and Melissa oil (lemon balm), to reduce agitation is accumulating $(27,28,29,30)$. But, in one randomized controlled trial (RCT) with strong methodology, Melissa oil had a $37 \%$ improvement in the NPI scores, the same as donepezil and placebo, which could be interpreted as touching and interacting with the patient having the main effect (31).

A discrepancy between the patient's capacity and the demands of the caregivers may trigger BPSD (32). So, the psychoeducation or support groups focusing on providing caregivers 


\section{Table 2. The non-pharmacological interventions for the treatment of BPSD}

- $\quad$ Cognitive Interventions

Cognitive Rehabilitation

Cognitive Stimulation Therapy

Computerized Cognitive Therapy

Reality Orientation Therapy

- Stimulant Based Interventions

Reminiscence Therapy

Validation Therapy

Music Therapy

Snoezolen (Multisensory stimulation)

Simulated Family Presence Therapy

Massage and Touch

Aromatherapy/Pet Therapy

- Social Activity/Social Interaction

- $\quad$ Physical Activity/Exercise/Dance

- Environmental Interventions

- Interventions For Caregivers and Stuff of Nursing Homes

Psychoeducation

Caregiver Support Group Therapy

Case Manegement/ Counselling

- Multicomponent Interventions

with knowledge of dementia, skills, and/or support to help them cope with the stress of caregiving may reduce the BPSD and even delay nursing home placement of the patient $(33,34)$.

Another non-pharmacological intervention is encouraging social and physical activity in the demented elderly, which is still one of the main strategies for the prevention of dementia $(35,36)$. In the real-life residential facilities and dementia clinics, non-pharmacological interventions, such as psychoeducation and support of the caregiver, providing social/physical activities for the elderly seems to be more easily put into practice.

\section{Pharmacological Treatment of BPSD}

Acetylcholinesterase inhibitors: Although most guidelines address adding or maximizing the dose of acetylcholinesterase inhibitors (ChEls) for the treatment of BPSD (17), the efficacy of ChEls is generally significant but small according to the RCTs and meta- and pooled analyses $(37,38,39,40,41)$.

Acetylcholinesterase inhibitors are more beneficial for depression/dysphoria, anxiety, and apathy/indifference $(42,43)$. However, some studies using ChEls suggest that ChEls did not confer any significant effect on clinically prominent agitation for short-term (3 months) treatment, which was speculated to be a subgroup of $A D$ patients with more treatment-resistant BPSD symptoms or the heterogeneous precipitants of agitation, such as environmental factors, sleep disorders, etc. $(44,45,46)$.
Albeit it not so effective in neuropsychiatric symptoms of Alzheimer's dementia, ChEls have shown more treatment benefits for the apathy, anxiety, and psychotic symptoms, such as visual hallucinations, in dementia with Lewy bodies (47).

In the absence of alternative safe and effective psychotropic options, currently, the use of ChEls is an appropriate pharmacological strategy for the management of BPSD in Alzheimer's disease.

Memantine: With regard to meta-analyses and pooled analyses, memantine has some advantages over placebo for the BPSD, such as agitation/aggression, irritability/lability, and psychosis $(48,49,50,51)$. In the most recent Cochrane meta-analysis, 2.76 points of decrease was reported on the 144-point NPI (95\% $\mathrm{Cl} 0.88$ to $4.63, \mathrm{P}=.004$ ) in patients with moderate to severe $A D$ with memantine, but no efficacy on NPI and activities of daily living was assessed for the mild to moderate $A D$ at 6 months (52). But, memantine was shown to be slightly less likely to develop agitation against placebo $(7.7 \%$ versus $9.3 \%$, OR .78, 95\% Cl .61 to $.99, \mathrm{P}=.04)(52)$. However, all this evidence has been drafted from the secondary outcomes. The only RCT evaluating the effect of memantine directly on clinically significant agitation (Cohen-Mansfield Agitation Inventory- CMAI score $\geq 45$ ) as primary outcome did not find any significant advantage of memantine versus placebo at Week 6 or 12. But, memantine showed a difference on the total NPI at Weeks $6(-6.9 ;-12.2$ to $-1.6 ; p=.012)$ and 12 $(-9.6 ;-15.0$ to $-4.3 p=.0005)$ (53). Another recently published trial, although having some sort of methodological limitations, did not find any efficacy of memantine on severe agitation as a primary outcome in community-dwelling elderly patients with moderate to severe Alzheimer's dementia (54). The effect of memantine for milder agitation in dementia has not been searched yet.

The evidence for the efficacy of combination therapy (ACEI and memantine combination) has been scarce for the BPSD as a primary outcome (55). One study did not find any benefit of donepezil and memantine combination therapy on cognition and behavior, either (56). The latest meta-analysis revealed a small but significant advantage of adding memantine to ACEl therapy on behavior and mood (SMD =-.17, 95\% Cl -.32 to -.03 ) and cognition (SMD=-.25, $95 \% \mathrm{Cl}-.36$ to -.14 ) but not on function/ADL at 6 months (57).

Antidepressants: Serotoninergic dysfunction has been shown to contribute to the pathogenesis of some BPSD symptoms, such as aggressive, impulsive behavior and psychosis (58). With the emerging data about the serious side effects of antipsychotics, antidepressants have been increasingly prescribed for the treatment of BPSD (59). For the treatment of BPSD, a recent Cochrane review analyzing 9 RCTs concluded that the SSRIs sertraline and citalopram were associated with a modest improvement in symptoms of agitation when compared to placebo, and SSRIs are well tolerated against placebo, typical antipsychotics, and atypical antipsychotics (60). 
Table 3. Psychotropics mainly used for the treatment of BPSD in elderly (Adapted from references $\mathbf{1 8 , 1 9 , 2 0 \text { ) }}$

\begin{tabular}{|lcccl|}
\hline Psychotropic & $\begin{array}{c}\text { Starting dose } \\
\text { (mg/day) }\end{array}$ & $\begin{array}{c}\text { Incremental dose } \\
(\mathbf{m g})\end{array}$ & $\begin{array}{c}\text { Average target } \\
\text { daily dose }\end{array}$ & Common side effects in elderly \\
\hline Antipsychotics & $.25-.5$ & $1-1.5$ & Sedation, extrapyramidal symptoms, metabolic \\
Risperidone & $25-.5$ & 2.5 & 5 & syndrome, falls, akatisia \\
Olanzapine & 2.5 & $12.5-25$ & 150 & \\
Quetiapine & $12.5-25$ & $2.5-5$ & $10-20$ & \\
Aripiprazole & $2.5-5$ & & & \\
Antidepressants & & 10 & $10-40$ & Gastrointestinal symptoms, anxiety, insomnia \\
Citalopram & 10 & 5 & $10-20$ & sexual dysfunction, OT prolongation, SIADH, \\
Essitalopram & 5 & 25 & $50-200$ & sedation \\
Sertraline & 25 & 15 & $15-45$ & \\
Mirtazapine & $7.5-15$ & 37.5 & $50-200$ & \\
Venlafaxine & 37.5 & 25 & & \\
Trazodone & 25 & & 1 & Sedation, falls, memory impairments, \\
& & .25 & 7.5 & dependence,rebound insomnia \\
Benzodiazepine/ Non-benzodiazepine Hypnotic & .25 & & & \\
Lorezapam & 3.75 & & & \\
Zopiclone & & & & \\
\hline
\end{tabular}

There have not been any statistically significant differences in the effectiveness between SSRIs and atypical or typical antipsychotics for the treatment of BPSD $(61,62)$.

The evidence for how long the antidepressants would be used for BPSD is lacking, although in recent small studies, discontinuation of antidepressants was associated with significantly worse depressive symptoms (63) and a significant worsening of neuropsychiatric symptoms (64).

There is still insufficient evidence on the long-term safety of antidepressant use for the elderly and for neuropsychiatric symptoms in patients with dementia, as well (65).

Although having some benefit for the treatment of BPSD, the meta-analysis and RCTs did not show any efficacy of SSRIs and mirtazapine for the depression in the dementia $(66,67,68)$. The lack of evidence for the efficacy of antidepressants in depression of dementia can be attributed to the diagnostic criteria of depression in dementia, because depression could be a symptom of dementia or a syndrome different from dementia, only having an overlapping symptom profile from the neurobiological perspective (68).

For milder depression, non-pharmacological interventions, such as physical activity and planned positive activities, may be recommended $(69,70)$. However, if moderate to severe depressive symptoms are apparent in dementia, antidepressants, such as SSRIs, venlafaxine, and mirtazapine, should be chosen (Table 3).

Trazodone has long been used as an augmenting agent in depression or as a relatively safe sleeping pill for insomnia (71). For the treatment of BPSD, 2 RCTs $(72,73)$ and a Cochrane review (74) examining the efficacy of trazodone demonstrated that trazodone with doses 50-300 mg per day was not different than placebo in efficacy or in adverse events. Trazodone could be preferred as a sedative drug for the insomnia and also agitation associated with insomnia in dementia patients at doses between 25-200 mg per day.

With the evidence of antidepressants having modest efficacy for BPSD and having additional benefit for depression and being more well tolerated than antipsychotics, starting an antidepressant with mild-moderate neuropsychiatric symptoms in Alzheimer's dementia is recommended $(70,75)$ (Figure 1). Which antidepressant is to be chosen generally for the BPSD and depression in dementia depends on drug interactions, side effects, and protein-binding capacity of the drugs (Table 3). Although they do not have any risk for the death in dementia patients, serotoninergic antidepressants have some serious adverse effects, such as falls, fractures (76), bleeding (77), and hyponatremia (78) in the elderly.

Antipsychotics: Antipsychotics had been widely used for BPSD treatment, especially because of their sedative properties. But, due to emerging data about the serious side effects and increased risk of mortality in patients with dementia (79), the percentage of antipsychotic usage for the BPSD has been eventually decreasing (59).

There have been not many studies about the typical antipsychotics for the treatment of BPSD. The typical antipsychotic haloperidol was shown to only improve agitation in dementia (80), and in another 6-month RCT, psychosis and hostile suspiciousness factors were decreased with haloperidol (81). Regarding serious side effects, such as cognitive worsening, tardive dys- 
Monitor about BPSD at every examination of dementia patient with a scale such as NPI

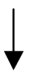

If any distressing BPSD, ask - how long? What brings the problem? Whom the behaviour is bothering? (Patient? Caregiver?)

- Evaluate for pain, delirium, infection, dehydration, diarrhea, drug side effects

- Evaluate visual and auditory impairment

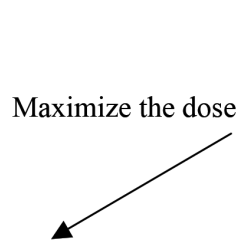

If the symptoms of BPSD that are not so severe

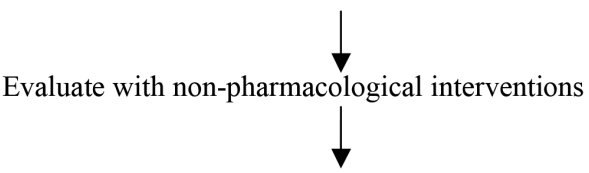

If BPSD are so severe causing harm to patient or the caregiver

If BPSD can not be controlled/reduced/ failed, add pharmacological treatment to on-going onpharmacological interventions

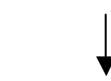

Depressed/Anxious

Antidepressants

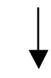

Psychotic

Antipsychotics

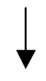

Agitation/Aggression

Antidepressants

Antipsychotics

Trazodone

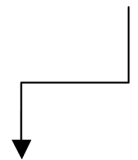

$\begin{array}{ll}\text { Antipsychotics } & \text { Mirtazapine } \\ \text { Trazodone } & \text { Zopiclone }\end{array}$

If co-morbid mild-moderate depression $\longrightarrow$ Non-pharmacologic interventions

If co-morbid severe depression $\longrightarrow$ Antidepressants

If acute agitation $\longrightarrow$ Short-term benzodiazepines/ im haloperidol/ im olanzapine

Initiate psychotropics with low dose and titrate slowly

Monitor for the side effects of psychotropics

Reassess for the response at 3-6 months intervals especially for the antipsychotics

If symptoms disappear, gradually decrease the dose and stop the psychotropic

Figure 1. Algorithm for the Diagnosing and Treatment of BPSD (adapted from the references 17,18,19,20) 
kinesia, and anticholinergic and cardiovascular side effects in the elderly, haloperidol is not recommended as the first choice. In harmful conditions, such as acute agitation/aggression and when the patient refuses oral forms, intramuscular haloperidol could be recommended only in low doses.

For the atypical antipsychotics, the latest meta-analysis including 16 RCTs, searching olanzapine, quetiapine, risperidone, clozapine, aripiprazole, and ziprasidone, reported a significant improvement in psychosis with risperidone and a significant improvement in aggression with risperidone and olanzapine treatment compared to placebo (82).

The effect of antipsychotics for cognition in dementia is another area for research. In a small RCT, compared to rivastigmine, quetiapine was associated with cognitive deterioration, even in low doses, such as $25-50 \mathrm{mg}$ per day in a 26 -week duration (83). But, the effect of atypical antipsychotics on cognition is still to be proven (84).

Both the typical and the atypical antipsychotics have been significantly increasing the mortality rates in dementia patients $(79,85)$. Haloperidol was associated with the highest mortality rates (relative risk $=1.54,95 \%$ confidence interval $[\mathrm{Cl}]=1.38$ 1.73 ), followed by risperidone, olanzapine (relative risk=.99, $95 \%$ $\mathrm{Cl}=.89-1.10$ ), and quetiapine (relative risk $=.73,95 \% \mathrm{Cl}=.67-.80$ ) (85). The mortality rates with haloperidol were highest during the first 30 days and decreased significantly over time in dementia out-patients. The mortality risk was also higher for haloperidol compared to risperidone in dementia patients residing in nursing homes (86). The mortality risk increases with higher doses of antipsychotics (86). Some studies have demonstrated contrary findings; a 5 -year retrospective study with data from 89,000 veterans showed that lower doses of atypical antipsychotics (olanzapine $<2.5 \mathrm{mg} / \mathrm{d}$, quetiapine $<50 \mathrm{mg} / \mathrm{d}$, and risperidone $<1 \mathrm{mg} / \mathrm{d}$ ) did not increase the mortality rates, but not haloperidol, even in low doses (87).

Besides increased mortality rates, antipsychotics have other serious side effects in dementia patients. Typical antipsychotics and risperidone have increased extrapyramidal side effects, and tardive dyskinesia risk. Atypical antipsychotics, but especially risperidone and olanzapine, have increased risk of stroke, myocardial infection, venous thrombo-emboli, and pneumonia. $(19,39,88,89)$.

Regarding the treatment of severe agitation/aggression and/or psychosis, most of the clinical practice guidelines recommend risperidone, olanzapine, and haloperidol if non-pharmacological approaches fail or fail in combination with both groups of anti-dementia drugs (17). However, antipsychotics are not yet approved for the treatment of BPSD in patients with dementia by the US Food and Drug Administration (FDA), and also, the FDA has warned about the risk of increased mortality and stroke with all antipsychotics in people with dementia. But, only risperidone is licensed for persistent aggression in patients with moderate to severe Alzheimer's dementia unresponsive to non-pharmacological interventions and when there is a risk of harm to self or others for the short-term treatment up to 6 weeks in the United Kingdom (90).

Because of the serious side effects of antipsychotics in dementia, the duration of antipsychotic treatment is still a question. As shown by some studies, such as DART-AD, discontinuing antipsychotics had no difference in the NPI scores and functional status than continuing the antipsychotic for the 6- and 12-month follow-up. The only significant deterioration in neuropsychiatric symptoms was seen in the patients with more severe behavioral symptoms (NPI scores>14) in the DART-AD study. But, the longer-term use of antipsychotics in the study was associated with increased mortality rate versus placebo in the follow-up (91). Another study investigated the relapse rates after discontinuation of risperidone for agitation/aggression and psychosis against placebo in $A D$ for 16 weeks. The study showed that relapse rates were higher for the group that was switched from risperidone to placebo than for the group continuing risperidone (48\% vs. $15 \% ; P=.02$; hazard ratio: $4.88 ; 95 \% \mathrm{Cl}: 1.08$ to 21.98; $P=.02$ ) (92). Also, earlier discontinuation of risperidone increased the risk of relapse (92). Newly released Cochrane meta-analysis results declared that patients having BPSD can be withdrawn from chronic antipsychotics without deteriorating effects on BPSD, but it remains uncertain whether withdrawal is beneficial for cognition or psychomotor status (93).

Because of the modest efficacy of antipsychotics, their benefits often still outweigh their risks in patients with BPSD. In the absence of other effective agents for BPSD, using antipsychotics cautiously and for the possible short term, after informing the patients and the families, is recommended. There should be an ongoing assessment of benefits versus harms, and consideration for withdrawing the medications should be made periodically, such as every 3 to 6 months $(17,18,19,20)$ (Figure 1).

Anticonvulsants: There have been only 2 RCTs with divalproex sodium (94,95), 1 RCT with carbamazepine (96), and 1 RCT with oxcarbazepine (97). One Cochrane meta-analysis about divalproex sodium examining agitation did not find any efficacy and also found higher adverse events versus placebo, such as sedation, falls, infection, and gastrointestinal disorders (98). One multi-center RCT using divalproex sodium did not delay emergence of agitation or psychosis or slow cognitive decline in patients with moderate Alzheimer disease for 24 months and was also associated with hippocampal and whole-brain volume atrophy (99). Recently, a small study with only 7 patients showed that low-dose gabapentin could be used for aggressive behaviors in vascular and Alzheimer dementia without adverse reactions (100).

One more review for mood stabilizers in BPSD (101) showed that CBZ is effective for BPSD at $300-600 \mathrm{mg}$ per day for $6-8$ weeks, especially for aggression and hostility. But, having serious adverse effects, such as fatal skin reactions, and also drugdrug interactions limits the use of CBZ for the BPSD. There has been scarce evidence for the other anticonvulsants. Nonethe- 
less, the guidelines have not addressed the anticonvulsants in the management of BPSD, and the use of anticonvulsants must be avoided with the emerging data about the side effects and significant toxic effects on the brain $(17,102)$.

Benzodiazepines: Although reported to be effective for aggression in dementia in former studies (103), serious side effects, such as daytime sedation, cognitive deterioration, and increased risk of falls in the elderly, restrained the use of benzodiazepines, especially the short- and intermediate-acting ones, for the demented and also for the healthy elderly (104).

According to a systematic appraisal of guidelines of management of BPSD, benzodiazepines are solely recommended in dementia guidelines when a patient with dementia has agitation/ aggression and/or psychosis but only for the short term (17). One RCT showed that intramuscular (im) lorazepam was effective for excitation in dementia only for 2 hours but not for 24 hours; im olanzapine had a sustained positive effect for 24 hours (105).

In daily clinical practice, when agitation/aggression or psychosis can not be controlled with non-pharmacological interventions and psychotropics, benzodiazepines with less inactive metabolites, such as lorazepam (.5-1 mg/day), could be prescribed as a p.r.n. agent for a short time (Table 3). Benzodiazepine use should be limited to only brief stressful episodes, such as change in residence or an anxiety-provoking event. At the same time, the continuing antipsychotic should be exchanged with a more potent one, or the dose of antipsychotic should be increased to a more effective dose.

Treatment of psychiatric and behavioral disturbances in dementia is complex and may require several interventions as part of a comprehensive care plan. The treatment of BPSD should be personalized for each patient to improve the neuropsychiatric symptoms and quality of life of the patient and also the caregiver.

Because of the modest efficacy of antipsychotics, their benefits often still outweigh their risks in patients with BPSD. In the absence of other effective agents for BPSD, using antipsychotics cautiously and for the possible short term, after informing the patients and the families, is recommended. There should be an ongoing assessment of benefits versus harms, and consideration for withdrawing the antipsychotics should be made periodically, such as every 3 to 6 months.

At present, the best strategy for the treatment of BPSD seems to be non-pharmacological interventions first, and if they do not work out, they can be combined with appropriate pharmacological interventions. Further investigations are needed for more effective and safer pharmacological treatment options, besides encouraging non-pharmacological interventions.

\section{References}

1. World Alzheimer Report 2009. London:Alzheimer's Disease International, 2009 (online). Available from URL: http://www.alz.co.uk/ research/files/WorldAlzheimerReport.pdf [accessed 2013 July]
2. Steinberg M, Sheppard JM, Tschanz JT, Norton MC, Steffens DC Breitner JC, Lyketsos CG. The incidence of mental and behavioral disturbances in dementia: the cache county study. J Neuropsychiatry Clin Neurosci 2003; 15:340-345. [CrossRef]

3. Finkel SI, Burns A. BPSD Consensus Statement, International Psychogeriatric Association. Finkel, S.I., Costa E, Silva, J., Cohen, G. 1996.

4. The IPA Complete Guides to BPSD- Specialists Guide, http://www. ipa-online.net/ipaonlinev4/main/publications/publications_other html,2010) [accessed 2013 July]

5. Steinberg M, Shao H, Zandi P, Lyketsos CG, Welsh-Bohmer KA, Norton MC, Breitner JC, Steffens DC, Tschanz JT; Cache County Investigators. Point and 5-year prevalence of neuropsychiatric symptoms in dementia: the Cache County Study. Int J Geriatr Psychiatry 2008; 23:170-177. [CrossRef]

6. Cerejeira J, Lagarto L, Mukaetova-Ladinska EB Behavioral and psychological symptoms of dementia. Frontiers in Neurology, May 2012, Volume 3, Article 73

7. Matsumoto $N$, Ikeda $M$, Fukuhara $R$, Shinagawa $S$, Ishikawa $T$, Mori T, Toyota $\mathrm{Y}$, Matsumoto T, Adachi $\mathrm{H}$, Hirono N, Tanabe $\mathrm{H}$. Caregiver burden associated with behavioral and psychological symptoms of dementia in elderly people in the local community. Dement Geriatr Cogn Disord 2007; 23:219-224. [CrossRef]

8. Steele C, Rovner B, Chase GA, Folstein M. Psychiatric symptoms and nursing home placement of patients with Alzheimer's disease. Am J Psychiatry 1990; 147:1049-1051. [CrossRef]

9. Tun SM, Murman DL, Long HL, Colenda CC, von Eye A. Predictive Validity of neuropsychiatric subgroups on nursing home placement and survival in patients with Alzheimer's Disease. Am J Geriatric Psychiatry 2007; 15:314-327. [CrossRef]

10. Sink KM, Covinsky KE, Barnes DE, Newcomer RJ, Yaffe K. Caregiver characteristics are associated with neuropsychiatric symptoms of dementia. J Am Geriatr Soc 2006; 54:796-803. [CrossRef]

11. Cummings JL, Mega M, Gray K, Rosenberg-Thompson $\mathrm{S}$, Carusi DA, Gornbein J. The Neuropsychiatric Inventory: comprehensive assessment of psychopathology in dementia. Neurology 1994; 44:2308-2314. [CrossRef]

12. NPI. http://npitest.net/about-npi.html [accessed 2013 July]

13. Hodgson NA, Gitlin LN, Winter L, Czekanski K. Undiagnosed illness and neuropsychiatric behaviors in community residing older adults with dementia. Alzheimer Dis Assoc Disord 2011; 25:109-115. [CrossRef]

14. Ballard C, Bannister C, Graham C, Oyebode F, Wilcock G. Associations of psychotic symptoms in dementia sufferers. Br J Psychiatry 1995; 167:537-540. [CrossRef]

15. Salzman C, Jeste DV, Meyer RE, Cohen-Mansfield J, Cummings J. Elderly patients with dementia-related symptoms of severe agitation and aggression: consensus statement on treatment options, clinical trials methodology, and policy. J Clin Psychiatry 2008; 69:889-898. [CrossRef]

16. Hogan DB, Bailey P, Black S, Carswell A, Chertkow H, Clarke B. Diagnosis and treatment of dementia: Nonpharmacologic and pharmacologic therapy for mild to moderate dementia. CMAJ 2008; 179:1019-1026. [CrossRef]

17. Azermai M, Petrovic M, Elseviers MM, Bourgeois J, Van Bortel LM, Vander Stichele RH Systematic appraisal of dementia guidelines for the management of behavioural and psychological symptoms. Ageing Res Rev 2012; 11:78-86. [CrossRef]

18. American Geriatric Society Dementia Algoritms. http://dementia. americangeriatrics.org/GeriPsych_index.php) [accessed 2013 July]

19. Tampi RR, Williamson D, Muralee S, Mittal V, McEnerney N, Thomas J, Cash M. Behavioral and Psychological Symptoms of Dementia: Part II-Treatment. Clinical Geriatrics; June 2011. 
20. Best Practice Guideline for Accommodating and Managing Behavioural and Psychological Symptoms of Dementia in Residential Care. A Person-Centered Interdisciplinary Approach. British Colombia. http://www.health.gov.bc.ca/library/publications/ year/2012/bpsd-guideline.pdf. [accessed 2013 July]

21. Lyketsos CG, Colenda CC, Beck C, Blank K, Doraiswamy MP, Kalunian DA, Yaffe K. Task Force of American Association for Geriatric Psychiatry. Position statement of the American Association for Geriatric Psychiatry regarding principles of care for patients with dementia resulting from Alzheimer disease. Am J Geriatr Psychiatry 2006; 14:561-572. [CrossRef]

22. Brodaty $\mathrm{H}$, Arasaratnam C. Meta-analysis of non-pharmacological interventions for neuropsychiatric symptoms of dementia. Am J Psychiatry 2012; 169:946-953. [CrossRef]

23. Gitlin LN, Kales HC, Lyketsos CG. Nonpharmacologic management of behavioral symptoms in dementia. JAMA 2012; 308:2020-2029. [CrossRef]

24. Olazarán J, Reisberg B, Clare L, Cruz I, Pe-a-Casanova J, Del Ser T, Woods B, Beck C, Auer S, Lai C, Spector A, Fazio S, Bond J, Kivipelto M, Brodaty H, Rojo JM, Collins H, Teri L, Mittelman M, Orrell M, Feldman HH, Mu-iz R. Nonpharmacological therapies in Alzheimer's disease: a systematic review of efficacy. Dement Geriatr Cogn Disord 2010; 30:161-178. [CrossRef]

25. Livingston G, Johnston K, Katona C, Paton J, Lyketsos CG. Old Age Task Force of the World Federation of Biological Psychiatry. Systematic review of psychological approaches to the management of neuropsychiatric symptoms of dementia. Am J Psychiatry 2005; 162:1996-2021. [CrossRef]

26. Bahar-Fuchs A, Clare L, Woods B. Cognitive training and cognitive rehabilitation for mild to moderate Alzheimer's disease and vascular dementia. Cochrane Database Syst Rev 2013; 6:CD003260.

27. Fu CY, Moyle W, Cooke M. A randomised controlled trial of the use of aromatherapy and hand massage to reduce disruptive behaviour in people with dementia. BMC Complement Altern Med 2013; 13:165. [CrossRef]

28. Fujii M, Hatakeyama R, Fukuoka Y, Yamamoto T, Sasaki R, Moriya M, Kanno M, Sasaki H. Lavender aroma therapy for behavioral and psychological symptoms in dementiapatients. Geriatr Gerontol Int 2008; 8:136-138. [CrossRef]

29. Jimbo D, Kimura Y, Taniguchi M, Inoue M, Urakami K. Effect of aromatherapy on patients with Alzheimer's disease. Psychogeriatrics 2009; 9:173-179. [CrossRef]

30. Ballard CG, O'Brien JT, Reichelt K, Perry EK. Aromatherapy as a safe and effective treatment for the management of agitation in severe dementia: the results of a double-blind, placebo-controlled trial with Melissa. J Clin Psychiatry 2002; 63:553-558. [CrossRef]

31. Burns A, Perry E, Holmes C, Francis P, Morris J, Howes MJ, Chazot $P$, Lees G, Ballard C. A double-blind placebo-controlled randomized trial of Melissa officinalis oil and donepezil for the treatment of agitation in Alzheimer's disease. Dement Geriatr Cogn Disord 2011; 31:158-164. [CrossRef]

32. Yamaguchi H, Maki Y, Yamagami T. Overview of non-pharmacological intervention for dementia and principles of brain-activating rehabilitation. Psychogeriatrics 2010; 10:206-213. [CrossRef]

33. Mittelman MS, Roth DL, Coon DW, Haley WE. Sustained benefit of supportive intervention for depressive symptoms in caregivers of patients with Alzheimer's disease. Am J Psychiatry 2004; 161:850-856. [CrossRef]

34. Mittelman MS, Ferris SH, Shulman E, Steinberg G, Levin B. A family intervention to delay nursing home placement of patients with Alzheimer disease. A randomized controlled trial. JAMA 1996; 276:1725-1731. [CrossRef]
35. Roth DL, Mittelman MS, Clay OJ, Madan A, Haley WE. Changes in social support as mediators of the impact of a psychosocial intervention for spouse caregivers of persons with Alzheimer's disease. Psychol Aging 2005; 20:634-644. [CrossRef]

36. Barnes DE, Santos-Modesitt W, Poelke G, Kramer AF, Castro C Middleton LE, Yaffe K. The Mental Activity and eXercise (MAX) trial: a randomized controlled trial to enhance cognitive function in older adults. JAMA Intern Med 2013; 173:797-804. [CrossRef]

37. Birks J. Cholinesterase inhibitors for Alzheimer's disease. Cochrane Database Syst Rev 2006; (1):CD005593.

38. Trinh NH, Hoblyn J, Mohanty S, Yaffe K. Efficacy of cholinesterase inhibitors in the treatment of neuropsychiatric symptoms and functional impairment in Alzheimer disease: a meta-analysis. JAMA 2003; 289:210-216. [CrossRef]

39. Seitz DP, Gill SS, Herrmann N, Brisbin S, Rapoport MJ, Rines J, Wilson K, Le Clair K, Conn DK. Pharmacological treatments for neuropsychiatric symptoms of dementia in long-term care: a systematic review. Int Psychogeriatr 2013; 25:185-203. [CrossRef]

40. Rodda J, Morgan S, Walker Z. Are cholinesterase inhibitors effective in the management of the behavioral and psychological symptoms of dementia in Alzheimer's disease? A systematic review of randomized, placebo-controlled trials of donepezil, rivastigmine and galantamine. Int Psychogeriatr 2009; 21:813-824. [CrossRef]

41. Sink KM, Holden KF, Yaffe K. Pharmacological treatment of neuropsychiatric symptoms of dementia: a review of the evidence. JAMA 2005; 293:596-608. [CrossRef]

42. Feldman H, Gauthier S, Hecker J, Vellas B, Xu Y, Ieni JR, Schwam EM. Donepezil MSAD Study Investigators Group. Efficacy and safety of donepezil in patients with more severe Alzheimer's disease: a subgroup analysis from a randomized, placebo-controlled trial. Int Psychogeriatr 2002; 14:389-404. [CrossRef]

43. Gauthier S, Feldman H, Hecker J, Vellas B, Ames D, Subbiah P, Whalen E, Emir B. Donepezil MSAD Study Investigators Group.Efficacy of donepezil on behavioral symptoms in patients with moderate to severe Alzheimer's disease. Int Psychogeriatr 2002; 14:389-404. [CrossRef]

44. Howard RJ, Juszczak E, Ballard CG, Bentham P, Brown RG, Bullock R, Burns AS, Holmes C, Jacoby R, Johnson T, Knapp M, Lindesay J, O'Brien JT, Wilcock G, Katona C, Jones RW, DeCesare J, Rodger M. CALM-AD Trial Group. Donepezil for the treatment of agitation in Alzheimer's disease. N Engl J Med 2007; 357:1382-1392. [CrossRef]

45. Ballard C, Corbett A, Chitramohan R, Aarsland D. Management of agitation and aggression associated with Alzheimer's disease: controversies and possible solutions. Curr Opin Psychiatry 2009; 22:532-540. [CrossRef]

46. Ballard C, Margallo-Lana M, Juszczak E, Douglas S, Swann A, Thomas A, O'Brien J, Everratt A, Sadler S, Maddison C, Lee L, Bannister C, Elvish R, Jacoby R. Quetiapine and rivastigmine and cognitive decline in Alzheimer's disease: randomised double blind placebo controlled trial. BMJ 2005; 330:874. [CrossRef]

47. McKeith I, Del Ser T, Spano P, Emre M, Wesnes K, Anand R, CicinSain A, Ferrara R, Spiegel R. Efficacy of rivastigmine in dementia with Lewy bodies: a randomised, double-blind, placebo-controlled international study. Lancet 2000; 356:2031-2036. [CrossRef]

48. Maidment ID, Fox CG, Boustani M, Rodriguez J, Brown RC, Katona CL. Efficacy of memantine on behavioral and psychological symptoms related to dementia: a systematic meta-analysis. Ann Pharmacother 2008; 42:32-38. [CrossRef]

49. Clerici F, Vanacore N, Elia A, Spila-Alegiani S, Pomati S, Da Cas R, Raschetti R, Mariani C; Memantine Lombardy Study Group. Memantine effects on behaviour in moderately severe to severe Alz- 
heimer's disease: a post-marketing surveillance study. Neurol Sci 2012; 33:23-31. [CrossRef]

50. Gauthier S, Loft H, Cummings J. Improvement in behavioural symptoms in patients with moderate to severe Alzheimer's disease by memantine: a pooled data analysis. Int J Geriatr Psychiatry 2008, 23:537-545. [CrossRef]

51. Wilcock G, Ballard C, Cooper J, Loft H. Memantine for agitation/ aggression and psychosis in moderately severe to severe Alzheimer's disease: a pooled analysis of 3 studies. J Clin Psychiatry 2008; 69:341-348. [CrossRef]

52. McShane R, Areosa Sastre A, Minakaran N. Memantine for dementia. Cochrane Database Syst Rev 2006; (2):CD003154.

53. Fox C, Crugel M, Maidment I, Auestad BH, Coulton S, Treloar A Ballard C, Boustani M, Katona C, Livingston G. Efficacy of memantine for agitation in Alzheimer's dementia: a randomised double-blind placebo controlled trial. PLoS One 2012; 7.

54. Herrmann N, Gauthier S, Boneva N, Lemming OM; 10158 Investigators. A randomized, double-blind, placebo-controlled trial of memantine in a behaviorally enriched sample of patients with moderate-to-severe Alzheimer's disease. Int Psychogeriatr 2013; 25:919-27. [CrossRef]

55. Hamuro A. Combination therapy with galantamine and memantine improves behavioral and psychological symptoms of dementia (BPSD) in patients with early-onset Alzheimer's disease. Aust N Z J Psychiatry 2013; 47:583. [CrossRef]

56. Howard R, McShane R, Lindesay J, Ritchie C, Baldwin A, Barber R, Burns A, Dening T, Findlay D, Holmes $C$, Hughes A, Jacoby R, Jones R, Jones R, McKeith I, Macharouthu A, O'Brien J, Passmore P, Sheehan B, Juszczak E, Katona C, Hills R, Knapp M, Ballard C, Brown R, Banerjee S, Onions C, Griffin M, Adams J, Gray R, Johnson T, Bentham P, Phillips P. Donepezil and memantine for moderate-to-severe Alzheimer's disease. N Engl J Med 2012; 366:893-903. [CrossRef]

57. Farrimond LE, Roberts E, McShane R. Memantine and cholinesterase inhibitor combination therapy for Alzheimer's disease: a systematic review. BMJ Open 2012; 2:e000917. [CrossRef]

58. Proitsi P, Lupton MK, Reeves SJ, Hamilton G, Archer N, Martin BM, lyegbe C, Hollingworth $\mathrm{P}$, Lawlor B, Gill M, Brayne C, Rubinsztein DC, Owen MJ, Williams J, Lovestone S, Powell JF. Association of serotonin and dopamine gene pathways with behavioral subphenotypes in dementia. Neurobiol Aging 2012; 33:791-803. [CrossRef]

59. Martinez C, Jones RW, Rietbrock S. Trends in the prevalence of antipsychotic drug use among patients with Alzheimer's disease and other dementias including those treated with antidementia drugs in the community in the UK: a cohort study. BMJ Open 2013; 3:e002080. [CrossRef]

60. Seitz DP, Adunuri N, Gill SS, Gruneir A, Herrmann N, Rochon P. Antidepressants for agitation and psychosis in dementia. Cochrane Database Syst Rev 2011; (2):CD008191.

61. Teranishi M, Kurita M, Nishino S, Takeyoshi K, Numata Y, Sato T, Tateno A, Okubo Y. Efficacy and Tolerability of Risperidone, Yokukansan, and Fluvoxamine for the Treatment of Behavioral and Psychological Symptoms of Dementia: A Blinded, Randomized Trial. J Clin Psychopharmacol 2013; 33:600-607. [CrossRef]

62. Henry G, Williamson D, Tampi RR. Efficacy and tolerability of antidepressants in the treatment of behavioral and psychological symptoms of dementia, a literature review of evidence. Am J Alzheimers Dis Other Demen 2011; 26:169-183. [CrossRef]

63. Bergh S, Selbæk G, Engedal K. Discontinuation of antidepressants in people with dementia and neuropsychiatric symptoms (DESEP study): double blind, randomised, parallel group, placebo controlled trial. BMJ 2012; 344:e1566.
64. Ballard C, Corbett A. A small proportion of people with dementia and neuropsychiatric symptoms experience clinically significant worsening when antidepressants are discontinued. Evid Based Med 2013; 18:27-28. [CrossRef]

65. Bakken MS, Engeland A, Engesæter LB, Ranhoff AH, Hunskaar S, Ruths S. Increased risk of hip fracture among older people using antidepressant drugs: data from the Norwegian Prescription Database and the Norwegian Hip Fracture Registry. Age Ageing 2013; 42:514-520.[CrossRef]

66. Banerjee S, Hellier J, Romeo R, Dewey M, Knapp M, Ballard C, Baldwin R, Bentham P, Fox C, Holmes C, Katona C, Lawton C, Lindesay J, Livingston G,McCrae N, Moniz-Cook E, Murray J, Nurock S, Orrell M, O'Brien J, Poppe M, Thomas A, Walwyn R, Wilson K Burns A. Study of the use of antidepressants for depression in dementia: the HTA-SADD trial--a multicentre, randomised, double-blind, placebo-controlled trial of the clinical effectiveness and cost-effectiveness of sertraline and mirtazapine. Health Technol Assess 2013; 17:1-166. [CrossRef]

67. Banerjee S, Hellier J, Dewey M, Romeo R, Ballard C, Baldwin R, Bentham P, Fox C, Wilson K, Burns A. Sertraline or mirtazapine for depression in dementia (HTA-SADD): a randomised, multicentre, double-blind, placebo-controlled trial. Lancet 2011; 378:403-411. [CrossRef]

68. Sepehry AA, Lee PE, Hsiung GY, Beattie BL, Jacova C. Effect of selective serotonin reuptake inhibitors in Alzheimer's disease with comorbid depression: a meta-analysis of depression and cognitive outcomes. Drugs Aging 2012; 29:793-806. [CrossRef]

69. Teri L, Gibbons LE, McCurry SM, Logsdon RG, Buchner DM, Barlow WE, Kukull WA, LaCroix AZ, McCormick W, Larson EB. Exercise plus behavioral management in patients with Alzheimer disease: a randomized controlled trial. JAMA 2003; 290:2015-2022. [CrossRef]

70. Ballard CG, Gauthier S, Cummings JL, Brodaty H, Grossberg GT, Robert P, Lyketsos CG. Management of agitation and aggression associated with Alzheimer disease. Nat Rev Neurol 2009; 5:245-255. [CrossRef]

71. Stahl SM. Essential Psychopharmacology Prescriber's Guide. Trazodone. 89. Cambridge University Press, 2005: 477-81.

72. Teri L, Logsdon RG, Peskind E, Raskind M, Weiner MF, Tractenberg RE, Foster NL, Schneider LS, Sano M, Whitehouse P, Tariot P, Mellow AM, Auchus AP, Grundman M, Thomas RG, Schafer K, Thal LJ; Alzheimer's Disease Cooperative Study. Treatment of agitation in AD: a randomized, placebo-controlled clinical trial. Neurology 2000; 55:1271-1278. [CrossRef]

73. Sultzer DL, Gray KF, Gunay I, Berisford MA, Mahler ME. A double-blind comparison of trazodone and haloperidol for treatment of agitation in patients with dementia. Am J Geriatr Psychiatry 1997; 5:60-69. [CrossRef]

74. Martinon-Torres G, Fioravanti M, Grimley EJ. Trazodone for agitation in dementia. Cochrane Database Syst Rev 2004;(4):CD004990.

75. Henry G, Williamson D, Tampi RR. Efficacy and tolerability of antidepressants in the treatment of behavioral and psychological symptoms of dementia, a literature review of evidence. Am J Alzheimers Dis Other Demen 2011; 26:169-183. [CrossRef]

76. Huang AR, Mallet L, Rochefort CM, Eguale T, Buckeridge DL, TambIyn R. Medication-related falls in the elderly: causative factors and preventive strategies. Drugs Aging 2012; 29:359-376. [CrossRef]

77. de Abajo FJ. Effects of selective serotonin reuptake inhibitors on platelet function: mechanisms, clinical outcomes and implications for use in elderly patients. Drugs Aging 2011; 28:345-367. [CrossRef]

78. Draper B, Berman K. Tolerability of selective serotonin reuptake inhibitors: issues relevant to the elderly. Drugs Aging 2008; 25:501-519. [CrossRef]

79. Schneider LS, Dagerman KS, Insel P. Risk of death with atypical antipsychotic drug treatment for dementia: meta-analysis of randomized placebo-controlled trials. JAMA 2005; 294:1934-1943. [CrossRef] 
80. Lonergan E, Luxenberg J, Colford J. Haloperidol for agitation in dementia. Cochrane Database Syst Rev 2002; (2):CD002852.

81. Devanand DP, Pelton GH, Cunqueiro K, Sackeim HA, Marder K. A 6-month, randomized, double-blind, placebo-controlled pilot discontinuation trial following response to haloperidol treatment of psychosis and agitation in Alzheimer's disease. Int J Geriatr Psychiatry 2011; 26:937-943. [CrossRef]

82. Ballard C, Waite J. The effectiveness atypical antipsychotics for aggression and psychosis in Alzheimer's disease. Cochrane Database Syst Rev 2006; (1):CD003476.

83. Ballard C, Margallo-Lana M, Juszczak E, Douglas S, Swann A, Thomas A, O'Brien J, Everratt A, Sadler S, Maddison C, Lee L,Bannister C, Elvish R, Jacoby R. Quetiapine and rivastigmine and cognitive decline in Alzheimer's disease: randomised double blind placebo controlled trial. BMJ 2005; 330:874. [CrossRef]

84. Rosenberg PB, Mielke MM, Han D, Leoutsakos JS, Lyketsos CG, Rabins PV, Zandi PP, Breitner JC, Norton MC, Welsh-Bohmer KA, Zuckerman IH, Rattinger GB, Green RC, Corcoran C, Tschanz JT. The association of psychotropic medication use with the cognitive, functional, and neuropsychiatric trajectory of Alzheimer's disease. Int J Geriatr Psychiatry 2012; 27:1248-1257. [CrossRef]

85. Kales HC, Kim HM, Zivin K, Valenstein M, Seyfried LS, Chiang C, Cunningham F, Schneider LS, Blow FC. Risk of mortality among individual antipsychotics in patients with dementia. Am J Psychiatry 2012; 169:71-79. [CrossRef]

86. Huybrechts KF, Gerhard T, Crystal S, Olfson M, Avorn J, Levin R, Lucas JA, Schneeweiss S. Differential risk of death in older residents in nursing homes prescribed specific antipsychotic drugs: population based cohort study. BMJ 2012; 344:e977. [CrossRef]

87. Rossom RC, Rector TS, Lederle FA. Are all commonly prescribed antipsychotics associated with greater mortaility in elderly male veterans with dementia? J Am Geriatr Soc 2010; 58:1027-1034. [CrossRef]

88. Zheng L, Mack WJ, Dagerman KS, Hsiao JK, Lebowitz BD, Lyketsos CG, Stroup TS, Sultzer DL, Tariot PN, Vigen C, Schneider LS. Metabolic changes associated with second-generation antipsychotic use in Alzheimer's disease patients: the CATIE-AD study. Am J Psychiatry 2009; 166:583-590. [CrossRef]

89. Herrmann N, Lanctôt KL. Do atypical antipsychotics cause stroke? CNS Drugs 2005; 19:91-103. [CrossRef]

90. Antipsychotics: Use in elderly people with dementia. Drug Safety Update. March 2009, vol 2 issue 8.

91. Ballard C, Lana MM, Theodoulou M, Douglas S, McShane R, Jacoby R, Kossakowski K, Yu LM, Juszczak E; Investigators DART AD. A randomised, blinded, placebo-controlled trial in dementia patients continuing or stopping neuroleptics (the DART-AD trial). PLoS Med 2008; 5:e76. [CrossRef]

92. Devanand DP, Mintzer J, Schultz SK, Andrews HF, Sultzer DL, de la Pena D, Gupta S, Colon S, Schimming C, Pelton GH, Levin B. Relapse risk after discontinuation of risperidone in Alzheimer's disease. N Engl J Med 2012; 367:1497-1507. [CrossRef]

93. Declercq T, Petrovic M, Azermai M, Vander Stichele R, De Sutter $\mathrm{Al}$, van Driel ML, Christiaens T.Withdrawal versus continuation of chronic antipsychotic drugs for behavioural and psychological symptoms in older people with dementia. Cochrane Database Syst Rev 2013; 3:CD007726.

94. Tariot PN, Raman R, Jakimovich L, Schneider L, Porsteinsson A, Thomas R, Mintzer J, Brenner R, Schafer K, Thal L; Alzheimer's Disease Cooperative Study; Valproate Nursing Home Study Group. Divalproex sodium in nursing home residents with possible or probable Alzheimer Disease complicated by agitation: a randomized, controlled trial. Am J Geriatr Psychiatry 2005; 13:942-949.

95. Porsteinsson AP, Tariot PN, Erb R, Cox C, Smith E, Jakimovich L, Noviasky J, Kowalski N, Holt CJ, Irvine C. Placebo-controlled study of divalproex sodium for agitation in dementia. Am J Geriatr Psychiatry 2001; 9:58-66. [CrossRef]

96. Tariot PN, Erb R, Podgorski CA, Cox C, Patel S, Jakimovich L, Irvine C. Efficacy and tolerability of carbamazepine for agitation and aggression in dementia. Am J Psychiatry 1998; 155:54-61. [CrossRef]

97. Sommer OH, Aga O, Cvancarova M, Olsen IC, Selbaek G, Engedal K. Effect of oxcarbazepine in the treatment of agitation and aggression in severedementia. Dement Geriatr Cogn Disord 2009; 27:155-163. [CrossRef]

98. Lonergan $\mathrm{E}$, Luxenberg J. Valproate preparations for agitation in dementia. Cochrane Database Syst Rev 2009; (3):CD003945.

99. Tariot PN, Schneider LS, Cummings J, Thomas RG, Raman R, Jakimovich LJ, Loy R, Bartocci B, Fleisher A, Ismail MS, Porsteinsson A, Weiner M, Jack CR Jr, Thal L, Aisen PS; Alzheimer's Disease Cooperative Study Group. Chronic divalproex sodium to attenuate agitation and clinical progression of Alzheimer disease. Arch Gen Psychiatry 2011; 68:853-861. [CrossRef]

100. Cooney C, Murphy S, Tessema H, Freyne A. Use of low-dose gabapentin for aggressive behavior in vascular and Mixed Vascular/ Alzheimer Dementia. J Neuropsychiatry Clin Neurosci 2013; 25:120-125. [CrossRef]

101. Yeh YC, Ouyang WC. Mood stabilizers for the treatment of behavioral and psychological symptoms of dementia: an update review. Kaohsiung J Med Sci 2010; 26:397-407.

102. Tariot PN, Schneider LS, Cummings J, Thomas RG, Raman R, Jakimovich LJ, Loy R, Bartocci B, Fleisher A, Ismail MS, Porsteinsson A, Weiner M, Jack CR Jr, Thal L, Aisen PS; Alzheimer's Disease Cooperative Study Group. Chronic divalproex sodium to attenuate agitation and clinical progression of Alzheimer disease. Arch Gen Psychiatry 2011; 68:853-861. [CrossRef]

103. Salzman C, Solomon D, Miyawaki E, Glassman R, Rood L, Flowers $\mathrm{E}$, Thayer S. Parenteral lorazepam versus parenteral haloperidol for the control of psychotic disruptive behavior. J Clin Psychiatry 1991; 52:177-180.

104. The American Geriatrics Society 2012 Beers Criteria Update Expert Panel. American Geriatrics Society Updated Beers Criteria for Potentially Inappropriate Medication Use in OlderAdults. http:// www.americangeriatrics.org/files/documents/beers/2012BeersCriteria_JAGS.pdf. [accessed July 2013]

105. Meehan KM, Wang H, David SR. Comparison of rapidly acting intramuscular olanzapine, lorazepam, and placebo: a double-blind, randomized study in acutely agitated patients with dementia. Neuropsychopharmacology 2002; 26:494. [CrossRef] 